\title{
The Role of CD4 Count in Determining Prognosis in HIV Infected Persons on Antiretroviral Therapy
}

\author{
Parul Salunke $^{1}$ and Shilpi Hora ${ }^{2^{*}}$ \\ ${ }^{1}$ Gurunank Hospital and Research Center, Mumbai, India \\ ${ }^{2}$ Jhalawar Medical College, Jhalawar, India \\ *Corresponding author
}

The CD4 count is estimated in HIV infected persons to stage HIV disease, determine disease progression and assess response to antiretroviral therapy (ART). A two-year prospective study was conducted to correlate the CD4 cell count with

\section{Keywords}

Antiretroviral therapy, CD4 count, HIV, Opportunistic infections, HIV prognosis

\section{Article Info}

Accepted:

28 January 2021 Available Online: 10 February 2021 clinicoimmunological recovery in HIV infected patients on ART. Methods: The baseline CD4 count and clinical profile of 1362 HIV seropositive patients (diagnosed using $3 \mathrm{E} / \mathrm{R} / \mathrm{S} /$ (Strategy III, NACO Guidelines) was determined, and patients with CD4 count $<350$ cells $/ \mu \mathrm{L}$ were started on ART. CD4 counts were reestimated after six and 12 months along with current clinical profile. Statistical analysis was done using the Chi-square test, and $\mathrm{p}<0.05$ was considered significant. Results: Sustained and consistent increase in CD4 count was seen in $84.9 \%$ of patients and in $94.7 \%$ of cases) on antiretroviral therapy after 6 months and 12 months of treatment, respectively, along with concomitant improvement in the clinical profile and reduction in the prevalence of OIs. Conclusions: The CD4 count is the hallmark surrogate marker for assessing prognosis in HIV infected patients. In untreated cases, CD4 counts decline and symptoms and OIs appear whereas after ART, patients that respond to treatment show consistent and sustained increase in CD4 count and improvement in clinical symptomatology.

\section{Introduction}

Many studies have shown that the CD4 T lymphocyte (CD4 cell) count is the best indicator of the immediate state of immunologic competence of an individual. It is one of the most widely used surrogate markers for monitoring disease progression and initiating antiretroviral therapy in HIV seropositive persons. The normal absolute count of CD4 $\mathrm{T}$ cells in healthy, HIV seronegative adults varies from 330 to 1600 cells $/ \mu \mathrm{L} .{ }^{1}$ Reference range for normal absolute CD4 count varies with race, ethnicity and gender. In a recent study, the reference range for normal absolute CD4 count for Indian male population was 381-1565 cells $/ \mu \mathrm{L}$, and for female population was 447 - 
1846 cells $/ \mu \mathrm{L}^{2}{ }^{2}$ In untreated HIV infection, the CD4 count declines by approximately $4 \%$ per year. ${ }^{3}$ Decline in CD4 counts and CD4 function is associated with development of clinical manifestations of HIV infection and opportunistic infections with endemic pathogens. ${ }^{4}$ The role of highly active antiretroviral therapy (HAART) in HIV infection is to rapidly and effectively reduce plasma HIV RNA levels in antiretroviralnaïve patients; this is usually accompanied by a gradual increase in CD4 cell counts, sometimes to near normal levels. In many patients, the CD4 cell counts increase to levels at which the patients are no longer generally susceptible to serious opportunistic infections. 5 Thus, CD4 counts are monitored in HIV infection for the following reasons:

- To estimate the level of immune competence of an individual.

- To stage HIV disease.

- To make decisions for initiating AntiRetroviral Therapy (ART).

- To monitor the progression of HIV disease and for prognosis in patients on ART.

-To initiate chemoprophylaxis against opportunistic infections.

As per National AIDS Control Organisation (NACO) guidelines, currently in India, absolute CD4 $\mathrm{T}$ cell count is used as the basis for initiation of ART. ${ }^{6}$ ART is recommended for all HIV infected individuals with CD4 counts $<250$ cells $/ \mu \mathrm{L}$ and for all symptomatic HIV infected individuals with CD4 counts between $250-350$ cells $/ \mu \mathrm{L}{ }^{7}$

This study was carried out to determine the pattern of CD4 $\mathrm{T}$ helper cell count in HIV seropositive adult patients on ART and to correlate the CD4 cell count with clinicoimmunological recovery in these patients.

\section{Materials and Methods}

A prospective study was conducted at a tertiary care hospital in Mumbai. A total of 1362 HIV seropositive cases, all above the age of 18 years attending the ICTC (Integrated Counseling and Testing Centre) in the Dept. of Microbiology were studied for a period of 2 years and their pattern of CD4 T cell count and clinical profile assessed after 6 months and 12 months of ART initiation. Individuals above 18 years of age, detected HIV seropositive as per NACO Guidelines, after pretest counseling and written informed consent, were included in the study and individuals below 18 years were excluded. Both microbiological and clinical parameters were studied.

\section{Microbiological parameters}

Clinically suspected cases and individuals visiting ICTC first underwent pretest counselling. Following this, a written, informed consent of the individual was taken. Then 3 to $4 \mathrm{ml}$ of blood was withdrawn aseptically from each client and testing for anti HIV antibodies was done as per Strategy III of NACO Guidelines 2007. The client's sample was subjected to three tests - ELISA/ Rapid/ Simple (E/ R/ S) employing different principles of test, or using different antigens if based on the same principle. The client was reported seropositive if all the three HIV tests $(\mathrm{E} / \mathrm{R} / \mathrm{S})$ were reactive. If the first test was positive and the second and third tests were negative, the client was reported as HIV seronegative. However, if two HIV tests (E/ $\mathrm{R})$ were reactive and the serum sample was non-reactive with the third assay, it was reported as indeterminate and the client was asked to visit after 2 weeks and the test was repeated as per NACO Guidelines. ${ }^{8}$

In the present study, Dot immunoassay, which employs the same principle as enzyme immunoassay (EIA), was used as the first test and if positive, the client's serum sample was subjected to two rapid tests. The combination of test kits provided by NACO, which was 
used for detecting HIV antibodies in our study were COMBAIDS (RS Advantage), Retroscreen HIV (QUALPRO Diagnostics), and Retroquic HIV (QUALPRO Diagnostics). After testing for anti HIV antibodies, clients underwent posttest counselling. HIV seropositive individuals were referred to the adult ART centre. Following clinical evaluation, the client was referred to the Dept. of Microbiology for CD4 count estimation. CD4 count was estimated when the client first reported to the ART centre (baseline), and thereafter every 6 months. In our study, we considered for analysis, the CD4 counts estimated at baseline, and after 6 months and 12 months of ART. CD4 count estimation was done on the BD FACS Count machine as per kit literature.

\section{Clinical parameters}

Clinical details of the clients i.e. personal details, date of detection of HIV seropositive status, possible route of transmission, symptoms and signs at the time of presentation, present symptoms and signs, presence of Opportunistic Infections (OIs), date of starting ART, and response to ART were recorded at each visit to the ICTC in a prescheduled proforma. Diagnosis of specific opportunistic infections was based on standard clinical diagnosis and laboratory procedures.

\section{Results and Discussion}

ART was initiated as per NACO Guidelines. Of the 634 study subjects who were on ART and followed-up after six months, 538 (84.9\%) had an increase in CD4 count, while the CD4 count decreased in $96(15.1 \%)$ cases; $x^{2}=30.44 ; \mathrm{p}<0.01$. An increasing trend in CD4 counts was seen in patients with all ranges of baseline $\mathrm{CD} 4$ values. Changes in CD4 count in HIV seropositive persons on ART after six months of ART are shown in Figure 1.

Of the 538 study cases showing a rise in CD4 count after six months of ART, in $61.7 \%$ the increase in $\mathrm{CD} 4$ count was by $>100$ cells $/ \mu \mathrm{L}$, while in $84.4 \%$ it was by $>50$ cells $/ \mu \mathrm{L}$ indicating good immunological response to ART. The CD4 count of 590 HIV seropositive clients on ART was assessed after 12 months of treatment. In 559 (94.74\%) cases a sustained increase in CD4 count was observed while $31(5.25 \%)$ cases showed a fall in CD4 count (Figure 2); $\chi^{2}=22.66 ; \mathrm{p}$ 100 cells $/ \mu \mathrm{L}$. Figure 2 depicts the changes in CD4 count in HIV seropositive cases on ART after 12 months of treatment.

Table.1 Immunological response to ART at 6 months

\section{Duration of ART}

Patients with increase in CD 4 count by $>100$ cells $/ \mu \mathrm{L}$

Patients with increase in CD 4 count by $>50$ cells $/ \mu \mathrm{L}$
6 months

$61.7 \%$

$84.4 \%$

Table.2 Immunological response to ART at 12 months

\section{Duration of ART}

Patients with increase in CD 4 count by $>100$ cells $/ \mu \mathrm{L}$

Patients with increase in CD4 count by $>50$ cells $/ \mu \mathrm{L}$
12 months

$70.8 \%$

$93.7 \%$ 
Figure.1 Changes in CD4 count in HIV seropositive persons on ART after six months of ART

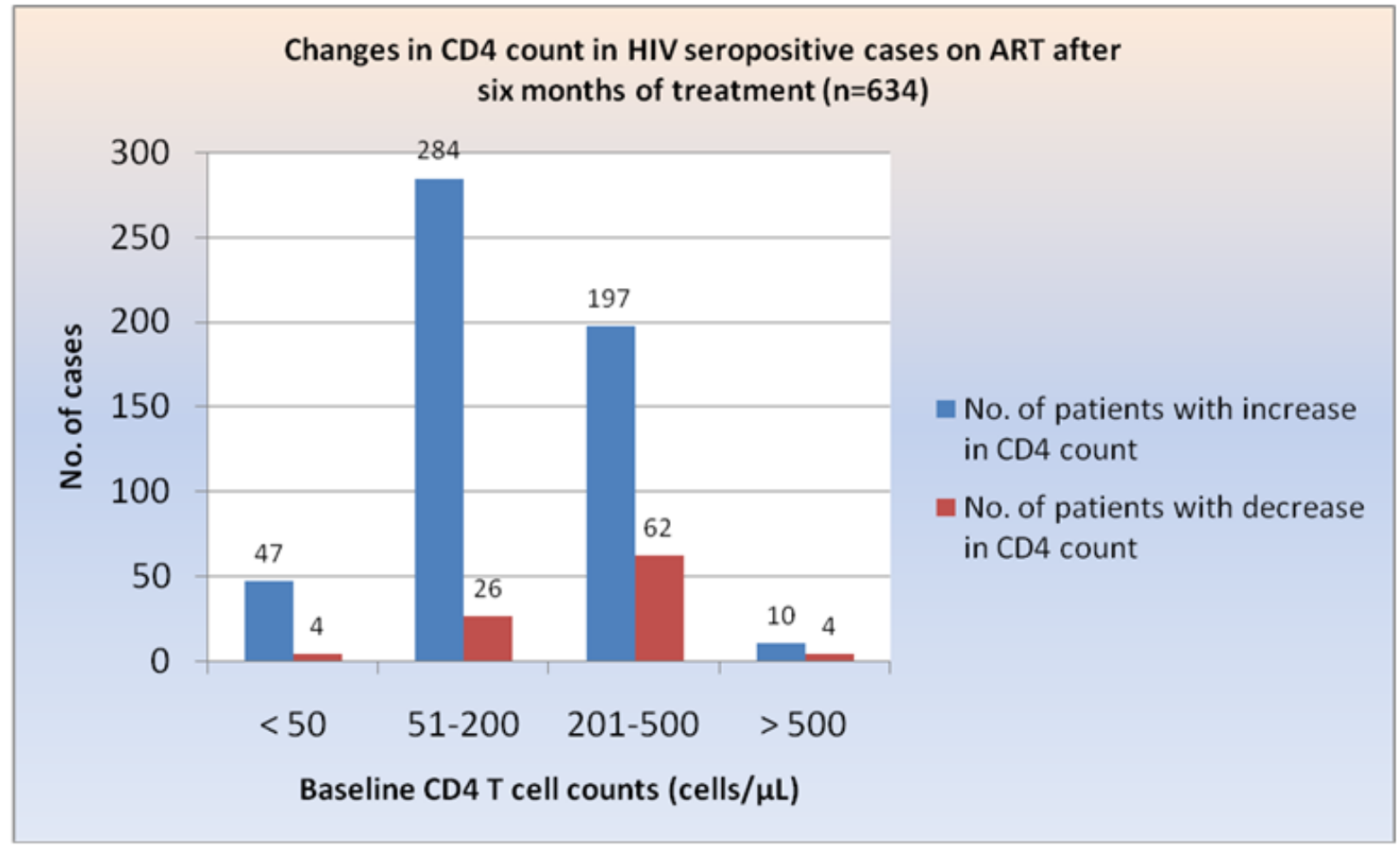

Figure.2 Changes in CD4 count in HIV seropositive cases on ART after 12 months of treatment

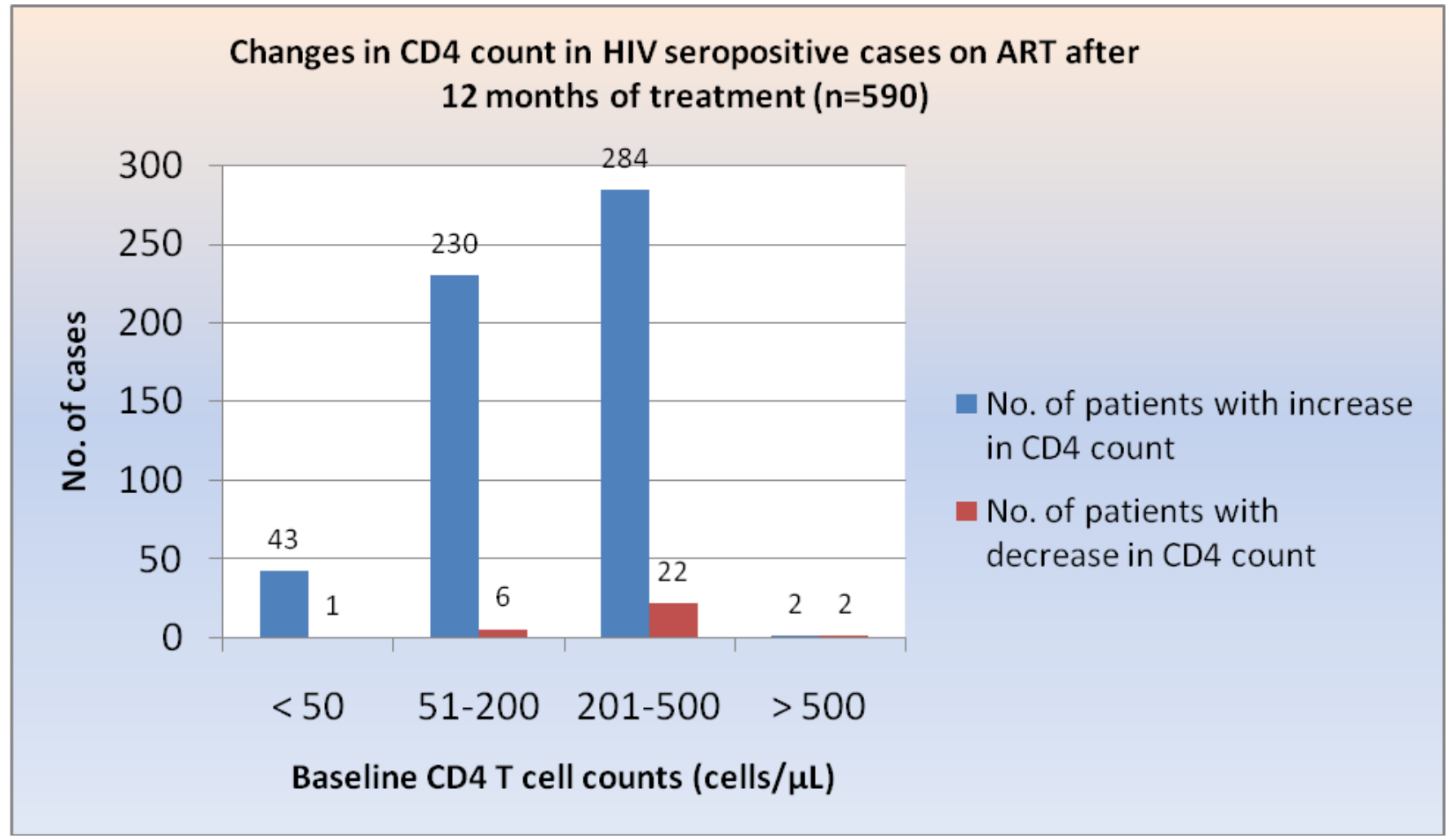


The prevalence of HIV infection in India has steadily declined since 2001-2003/2004, which was considered the peak of the HIV epidemic in India, from 0.38 per cent $(0.31$ $0.47)$ to 0.26 per cent $(0.22-0.32 \%)$ in $2015 .{ }^{9}$ This trend is primarily due to a decrease in the incidence of HIV while deaths due to HIV continue to decrease with effective ART. India has demonstrated an overall reduction of $57 \%$ in estimated annual new HIV infections (among adult population) during the past decade from 2.74 lakh in 2000 to 1.16 lakh in 2011. ${ }^{10}$

CD4 counts are a measure of the immune competence of an individual; CD4 counts decrease in HIV infection and symptoms of HIV infections and OIs appear. In our study $81.8 \%$ cases were symptomatic and $52.9 \%$ of symptomatic cases had CD4 counts < 200 cells/ $\mu \mathrm{L}$. In the study by Chakravarty et al., at CD4 $<200$ cells $/ \mu \mathrm{L}$, all cases $(100 \%)$ were symptomatic. ${ }^{11}$ OIs modify $\mathrm{T}$ lymphocyte subsets, and these changes combined with the immune defects due to HIV disease per se, cause faster progression of HIV disease. In our study, asymptomatic persons would have a slower progression of HIV disease than symptomatic cases. Persons who do not develop any OIs or clinical symptoms have a substantially longer duration of survival even with relatively low CD4 counts of $<50$ cells/ $\mu \mathrm{L}$ than those who develop OIs. ${ }^{12}$ When OIs strike, endemic pathogens are usually involved. ART directly affects the activity of HIV in the body and lowers the viral load. With less HIV present, the body is able to produce more CD4 cells and improve the immune system. Response to ART was assessed by determination of CD4 $\mathrm{T}$ lymphocyte count every six months. After six months of ART, an increase in CD4 count was seen in $84.9 \%$ cases. Significant relationship was established between ART and the increase in CD4 count using the $x^{2}$ test ( $\mathrm{p}<0.01)$. The decrease in CD4 count, found in $15.5 \%$ of clients in our study, may be due to adverse drug effects, drug intolerance, non-adherence to ART drugs, non-efficacy of treatment and the strain of HIV. ${ }^{13}$

In response to successful ART, CD4 counts typically increase by $>50$ cells $/ \mu \mathrm{L}$ within weeks of viral suppression.19 In our study, the increase in CD4 count was by > 50 cells $/ \mu \mathrm{L}$ in $84.4 \%$ cases indicating good immunological response to ART. In the study by Gautam et al., $84 \%$ cases showed an increase in CD 4 count by $>50$ cells $/ \mu \mathrm{L}$ which is in concordance with our study. ${ }^{14} \mathrm{An}$ appraisal in CD4 count of $<50$ cells $/ \mu \mathrm{L}$ is not significant. In multivariate analyses, an increment of $<50$ cells $/ \mu \mathrm{L}$ is independently associated with higher baseline CD4 cell count, older age, lower baseline viral load, and a viral load of $>400$ copies $/ \mathrm{ml}$ at any follow-up time-point. ${ }^{15}$ After 12 months of ART, $94.74 \%$ clients had a sustained increase in their CD4 count while $5.25 \%$ had a fall in their CD4 count. Significant relationship was established between ART and the increase in CD4 count using the ${ }^{2}$ test $(\mathrm{p}<0.01)$. The rise in CD4 count was significant (> 50 cells $/ \mu \mathrm{L}$ ) in $93.7 \%$ cases. Lawn SD et al., reported an increase in CD4 count, from a median of $97 \mathrm{cells} / \mu \mathrm{L}$ at baseline, to 261 cells $/ \mu \mathrm{L}$ at 48 weeks of $1 \mathrm{st}$ line ART. HIV infected individuals with baseline CD4 count $<50$ cells $/ \mu \mathrm{L}$ have an equal or greater capacity for immunological recovery in the 1st year of ART compared to those with higher baseline CD4 counts. However, in these cases, the CD4 counts remain $<200$ cells $/ \mu \mathrm{L}$ for a longer duration potentially increasing their risk of morbidity and mortality in the 1st year of ART. ${ }^{16}$

Once CD4 T lymphocyte counts exceed 200 cells/ $\mu \mathrm{L}$ for 3 to 6 months, there are reduced risks of many OIs and prophylaxis against 
certain pathogens can often be stopped. However, in many patients OIs persist even after 12 months of ART due to a low baseline CD4 count, further decreases in CD4 count or suboptimal control of virologic replication. ${ }^{17}$

\section{References}

1. M K Maini, R J Gilson, N Chavda, S Gill, A Fakoya, E J Ross et al., Reference ranges and sources of variability of CD4 counts in HIV-seronegative women and men. Genitourin Med. 1996 February; 72(1): 27-31.

2. Thakar MR, Abraham PR, Arora S, Balakrishnan P, Bandyopadhyay B, Joshi AA et al., Establishment of reference $\mathrm{CD} 4+\mathrm{T}$ cell values for adult Indian population. AIDS Res Ther. 2011 Oct 3; 8: 35. Available at: http://www.ncbi.nlm.nih.gov/pubmed/2 1967708. Accessed on 9/03/2013.

3. Betts M R, Ambrozak D R, Douek D C, Bonhoefer S. Analysis of total Human Immunodeficiency Virus (HIV) specific CD4+ and CD8+ T-cell responses: Relationship to viral load in untreated HIV infection. Journal of Virology 2001; 11983-91.

4. Clinical Overview of HIV Disease. HIV Insite Knowledge Base Chapter. January 2006. HIV Insite.com

5. Yeni P G, Hammer S M, Carpenter C C Cooper D A, Fischl M A, Gatell J M et al., Antiretroviral treatment for adult HIV infection in 2002: Updated recommendations of the International AIDS Society - USA panel. JAMA 2002; 288: 222-31.

6. Gautam H, Balla P, Saini S, Dewan R. Correlation between baseline CD4+T lymphocyte count and plasma viral load in AIDS patients and their early clinical and immunological response to HAART: A preliminary study. Indian J Med Microbiol 2008; 26: 256-8.
7. Sogarwal R, Bachani D. Are persons living with HIV timely accessing ARTservices in India? J Indian Med Assoc 2009; 107: 288-90.

8. Antiretroviral Thearpy Guidelines for HIV infected Adults and Adolescents including Post-exposure (NACO Guidelines 2015).

9. Pandey A, Dhingra N, Kumar P, et al., Sustained progress, but no room for complacency: Results of 2015 HIV estimations in India. Indian $\mathbf{J}$ Med Res. 2017; 146(1): 83-96.

10. NACO Annual report 2013-14. Available at http://naco.gov.in/NACO/Quick Links/Publication/Annual_Report/NAC O_Annual_Report/Ann ual_Report_2013-14/. Accessed on 28/06/2015.

11. Chakravarty J, Mehta H, Parekh A, Attili S, Agarwal NR, Singh SP et al., Study on clinicepidemiological profile in HIV patients in Eastern India. JAPI 2006; 854-7.

12. Kumarasamy N, Solomon S, Flanigan P, Hemalatha R, Thyagarajan SP, Mayer KH. Natural history of HIV disease in Southern India. Clinical Infectious Disease 2003; 36: 79-85.

13. Kannangai R, Kandathil AJ, Ebenezer DL, Nithyanandam G. Evidence for lower CD4 $\mathrm{T}$ cell and higher viral load in asymptomatic HIV1 infected individuals of India: Implications for therapy initiation. Indian $\mathrm{J}$ Med Microbiol 2008; 26: 217-21.

14. Betts MR, Ambrozak DR, Douek DC, Bonhoefer S. Analysis of total Human Immunodeficiency Virus (HIV) specific CD4 and CD8 T cell responses: Relationship to viral load in untreated infection. Journal of Virology 2001; 11983-91.

15. Gautam H, Balla P, Saini S, Dewan R. Correlation between baseline CD4 $\mathrm{T}$ lymphocyte count and plasma viral load 
in AIDS patients and their early clinical and immunological response to HAART: A preliminary study. Indian J Med Microbiol 2008; 26: 256-8.

16. Lawn SD, Myer L, Bekker LG, Wood R. CD4 cell recovery among HIV infected patients and very advanced immunodeficiency commencing antiretroviral treatment in sub-Saharan
Africa. BMC Infect Dis 2006; 6: 59.

17. Yeni PG, Hammer SM, Carpenter CC, Cooper DA, Fischl MA, Gatell JM et al., Antiretroviral treatment for adult HIV infection in 2002: Updated recommendations of the International AIDS Society - USA panel. JAMA 2002; 288: 222-31.

\section{How to cite this article:}

Parul Salunke and Shilpi Hora. 2021. The Role of CD4 Count in Determining Prognosis in HIV Infected Persons on Antiretroviral Therapy. Int.J.Curr.Microbiol.App.Sci. 10(02): 3545-3551. doi: https://doi.org/10.20546/ijcmas.2021.1002.390 